\title{
SALUD INTEGRAL Y MIGRACIÓN: ABORDAJE TRANSCULTURAL DEL PROCESO ENFERMERO EN UN CASO CLÍNICO DEL PROGRAMA DE SALUD MIGRATORIA DE GINEBRA, SUIZA
}

\author{
INTEGRAL HEALTH AND MIGRATION: CROSS CULTURAL APPROACH OF THE NURSING PROCESS IN A \\ CLINICAL CASE OF THE MIGRATORY HEALTH PROGRAM OF GENEVA, SWITZERLAND
}

SAÚDE INTEGRAL E MIGRAÇÃO: ABORDAGEM INTERCULTURAL DO PROCESSO DE ENFERMAGEM EM UM CASO CLÍNICO DO PROGRAMA DE SAÚDE MIGRATÓRIA DE GENEBRA, SUÍÇA

\section{Katia Marina}

Universidad de la República. Montevideo, Uruguay.

DOI: https://doi.org/10.22235/ech.v6i2.1512

katiamarinacom@gmail.com

Recibido: 05/04/2017

ORCID: 0000000285134221

Aceptado: 10/11/2017

\section{RESUMEN}

La ola migratoria que se inició en Europa en 2015 alteró notablemente la relativa estabilidad política y social asentada desde hacía más de una década en el continente. El aumento inesperado de la cantidad de refugiados y su procedencia extra europea, sus diferencias culturales y lingüísticas y los motivos trágicos de su exilio, no podían sino plantear nuevos y urgentes retos en cuanto a su integración y atención socio sanitaria en los Estados de destino. Suiza recibió entre 2011 y 2016 más de 140.000 solicitudes de asilo y 2015 fue el año de mayor afluencia con casi 40.000 solicitudes, contra poco más de 27.000 en 2016. El 5,6\% del total nacional fue asignado al Cantón de Ginebra, donde todo individuo relacionado con el trámite de asilo es asistido por programas de atención socio sanitaria públicos y específicos, que garantizan su accesibilidad a todos los servicios de salud. El objetivo es, a través del Modelo Transcultural de los Cuidados Enfermeros, poner de manifiesto aspectos relevantes de la atención sanitaria de solicitantes de asilo e identificar la incidencia del abordaje transcultural en la elaboración del plan de cuidados. Este trabajo se presenta como un estudio descriptivo de corte transversal y se basa en el Proceso Enfermero de un caso clínico, realizado en el Programa de Salud Migratoria de Ginebra, en enero de 2017.

Palabras clave: Enfermería Transcultural, Emigración e Inmigración, Asilo, Refugiados, Accesibilidad a los Servicios de Salud, Suiza

\section{ABSTRACT}

The migratory wave that began in Europe in 2015 markedly modified the relative political and social stability that had been established in the continent for more than a decade. The abrupt increase in the number of refugees and their extra-European origin, their cultural and linguistic differences and the tragic reasons of their exile, could not but raise new and urgent challenges in terms of their integration and sociohealth care in the States of destination. Switzerland received more than 140,000 asylum applications between 2011 and 2016 and 2015 was the year of greatest influx with almost 40,000 applications, versus just over 27,000 in 2016 . $5.6 \%$ of the country's total was allocated to the canton of Geneva, in which specific health care programs assisted them. This work is based on the Nursing Process of a clinical case carried out in the Migratory Health Program of the Canton of Geneva, in January 2017. The objective is, through the Cross-Cultural Model of Nursing Care, to highlight aspects of care health of asylum seekers and identify the impact of the cross-cultural approach in the Health Process of this population.

Keywords: Transcultural Nursing, Emigration and Immigration, Asylum, Refugees, Health Services Accessibility, Switzerland 


\section{RESUMO}

A onda migratória que começou na Europa em 2015 modificou marcadamente a relativa estabilidade política e social que havia sido estabelecida no continente por mais de uma década. $\mathrm{O}$ aumento abrupto do número de refugiados e a sua origem extra-europeia, as suas diferenças culturais e linguísticas e as trágicas razões do seu exílio não poderiam deixar de criar desafios novos e urgentes em termos de integração e cuidados sócio-sanitários em os Estados de destino. A Suíça recebeu mais de 140 mil pedidos de asilo entre 2011 e 2016 e 2015 foi o ano do maior afluxo com quase 40 mil pedidos, contra pouco mais de 27 mil em 2016. Foram atribuídos 5,6\% do total do país ao cantão de Genebra, em que específicos Os programas de cuidados de saúde os assistiram. Este trabalho baseia-se no Processo de Enfermagem de um caso clínico realizado no Programa de Saúde Migratório do Cantão de Genebra, em janeiro de 2017. O objetivo é, através do Modelo Transcultural de Cuidados de Enfermagem, destacar aspectos da saúde do cuidado de requerentes de asilo e identificar o impacto da abordagem transcultural no Processo de Saúde desta população

Palavras-chave: Enfermagem Transcultural, Emigração e Imigração, Asilo, Refugiados, Acesso aos Serviços de Saúde, Suíça

\section{INTRODUCCIÓN}

Entre los mitos fundacionales helvéticos son reconocidos el de la cultura del consenso, la coexistencia pacífica entre comunidades lingüísticas muy diversas y su estatuto de país neutral, reconocido en 1815 como garantía de integridad e inviolabilidad de su territorio. Suiza debe además su reputación humanitaria a la fundación (1863) y acción de la Cruz Roja Internacional y ambas imágenes se superponen hasta en sus banderas: cruz blanca sobre fondo rojo para Suiza y cruz roja sobre fondo blanco para la Cruz Roja Internacional (1). Adyacentes a estos mitos se halla el de Suiza tierra de asilo, que enlaza la temática actual de la inmigración con la política migratoria estatal. Este mito hunde sus raíces en una tradición de hospitalidad, que desde el siglo XVII y hasta principios del XX se les brindó a víctimas de persecuciones religiosas y políticas, refugiados cuyo capital y conocimientos técnicos beneficiaron considerablemente la economía y la intelectualidad suizas (1).

El siglo XX y sus conflictos globalizados trajeron nuevas problemáticas migratorias al Estado y muy controvertida fue su política durante la Segunda Guerra Mundial, cuando se rechazaron a refugiados judíos por no constituir su religión un motivo suficiente para otorgarles el asilo político (2). La segunda mitad del siglo aportó una inmigración económica proveniente del sur de Europa y finalizó en los 90 con la llegada de refugiados de los Balcanes durante las guerras de Yugoslavia y Kosovo.

La inmigración balcánica resultó ser precursora de la ola de 2015 y 2016, en la medida en que se trata en ambos casos de una inmigración de índole bélica y política, en la que intervienen factores socio-económicos subyacentes. Mientras que el origen de la primera permaneció acotado a países europeos, implicando determinada interfaz cultural con el país de destino, la segunda desestabilizó considerablemente la política y sociedad suizas, en parte por sus proporciones, pero sobre todo por su diversidad geográfica y socio-económica, sus diferencias culturales y lingüísticas y las circunstancias dramáticas que la desataron. Esta nueva configuración planteó por lo tanto la necesidad de una adaptación urgente del sistema de atención socio-sanitaria a poblaciones con características bio-psico-sociales y culturales muy particulares.

En cuanto a política migratoria, las bases legales del derecho de asilo suizo son las dictadas por la Ley nacional de asilo de 1998 y la Convención de Ginebra de 1951. Ambas determinan que la cualidad de refugiado es atribuida en forma individual a "quienes, en su Estado de origen o de su última residencia son expuestos a serios perjuicios o temen serlo en forma justificada, debido a su raza, religión, nacionalidad, pertenencia a determinado grupo social u opiniones políticas" (3). El derecho de asilo es de la competencia exclusiva de la Confederación y los cantones son los ejecutores de sus decisiones. Una vez presentada la solicitud y conformado el expediente, la residencia y atención de los solicitantes son atribuidas a uno de los 26 cantones, hasta el fallo de las autoridades federales. Los menores no acompañados (MNA por Mineurs non accompagnés) son evaluados mediante un procedimiento especial, ya que estos casos se contemplan en virtud del interés superior del niño (4).

27.207 solicitudes fueron registradas en 2016 , lo cual llevó la población total vinculada con el asilo (refugiados reconocidos, solicitantes y rechazados) a 118.284 personas, cerca del $1,5 \%$ de la población nacional. 5.178 (19\%) personas provenían de Eritrea, 3.229 (11.9\%) de Afganistán, 2.144 (7.9\%) de Siria, 1.581 (5.8\%) de Somalia y 1.373 (5.0\%) de Sri Lanka. Irak figura en sexta posición, con 1.312 solicitudes (4.8\%), seguido por Nigeria con 1.106 (4.1\%) y Gambia con 1.054 personas (3.9\%). Etiopía (1.036) y Guinea (900) ocupan respectivamente el noveno y décimo rango (5).

En un total de 31.299 casos tratados en primera instancia para 2016 , el $19 \%$ (5.985) de las solicitudes fueron aceptadas, el $35 \%$ (10.983) rechazadas, mientras que el 30\% (9.393) cayeron bajo la sanción de una No Admisión al Trámite (Non Entrée en Matière abreviado en NEM), ya que los solicitantes no presentaron documentos de identidad, o fueron previamente registrados en otro país de la Unión Europea (5). En efecto, la Convención de Dublín, que rige los procesos de postulación al asilo, estipula que todo trámite debe ser realizado en el país oficial de ingreso a la Unión Europea, Grecia e Italia en su gran mayoría.

De los solicitantes NEM o rechazados, 7.369 (23,5\%) obtuvieron una admisión provisional por conflictos vigentes en los países de origen o, en algunos casos, por razones médicas que exigían un tratamiento médico inmediato (5). Una vez resuelta la causa de la prórroga, una sanción de apoyo a la expulsión inmediata (soutien au renvoi immédiat) puede ser pronunciada en cualquier momento por la autoridad federal. Si bien pueden legalmente apelar contra ella, la gran mayoría de los solicitantes rechazados que no abandonan el territorio, sea por voluntad propia o bajo custodia en vuelos especiales, pasan a 
la ilegalidad. Acorde a la repartición decidida por la Confederación, el cantón de Ginebra recibe el 5,6\% del flujo migratorio nacional (6). Esto significó para el 20161.656 entradas, llevando el número de individuos transitando por el proceso de asilo a 4.393 a finales de año, a las cuales se sumaron 2.556 que obtuvieron el estatuto de refugiado. Para una población total de 493.706 personas, la demografía del asilo representó 1,4\%, prevaleciendo al igual que a nivel nacional solicitantes de Eritrea, Afganistán, Siria, Somalia y Sri Lanka (7).

\section{PROGRAMA DE SALUD MIGRATORIA (PROGRAMME SANTÉ MIGRANTS) EN GINEBRA}

Toda persona que transita por el trámite de asilo es amparada por el Estado en su atención socio sanitaria (alojamiento, salud, aprendizaje del idioma y escolaridad de los niños) a través y a criterio de los cantones, según una repartición de los costos regida por la Ley de Asilo (LAsi). Ginebra y su vecino Vaud son los únicos en incluir la atención socio sanitaria de los solicitantes de asilo dentro de su política pública, mientras que los demás cantones delegan estos aspectos a ONG's (8).

El Programa de Salud Migratoria (PSM) fue creado en 1993 a iniciativa de la Cruz Roja ginebrina y vinculado a los Hospitales Universitarios de Ginebra (HUG) a partir de 1999, dentro del Departamento de Medicina Comunitaria, de Atención Primaria y de Emergencia (Médecine Communautaire, de Premier Recours et des Urgences) (9). EI PSM forma parte de la Red Salud para Todos (Réseau Santé pour Tous) de los HUG y atiende a toda persona relacionada con el proceso de asilo, ya sean refugiados reconocidos, solicitantes en trámite o rechazados y personas en situación de clandestinidad. Su misión apunta a "garantizar la calidad y seguridad de los cuidados, teniendo en cuenta las barreras lingüísticas, socioeconómicas y culturales que puedan limitar la accesibilidad de la población diana al sistema de cuidados" (10). Sus acciones son coordinadas en conjunto y se llevan a cabo desde distintas estructuras geográficamente repartidas en el cantón.

L'Accueil du Bouchet es el punto de llegada de los solicitantes asignados al cantón de Ginebra y lugar donde se realiza la primera consulta de Enfermería, sin servicio de intérprete. En ésta se lleva a cabo una breve anamnesis y exploración física para la detección de las enfermedades infecto contagiosas más prevalentes en esta población, en particular escabiosis y tuberculosis. Esta primera instancia sanitaria, exclusivamente manejada por Enfermería, tiene por objetivo establecer las bases de un vínculo terapéutico de confianza, así como orientar a los recién llegados hacia las siguientes etapas de su proceso de atención.

El alojamiento de los solicitantes es de autoridad del Servicio Social (Hospice Général) del Cantón de Ginebra. Éstos son integrados a una vivienda en función de la conformación del núcleo familiar: parejas o madres con hijos permanecen en hogares, mientras que varones solteros son dirigidos transitoriamente hacia refugios subterráneos antiatómicos acondicionados para vivienda. La mayoría de los hogares, cuya capacidad pue- de rondar los 400 cupos, cuentan con atención de Enfermería del PSM. Esta se traduce por un servicio de consultas sin número, un seguimiento por agenda para casos particulares y la realización de una Evaluación de Salud Inicial (ESI), consulta profundizada de una hora y media de duración con servicio de intérprete. En esta segunda instancia se profundizan los puntos abordados en el Accueil du Bouchet, agregando aspectos psicosociales, vinculados con la trayectoria migratoria y los eventuales traumatismos sufridos en su transcurso. A partir de la ESI se implementa un proceso de atención integral, que incluye la atribución de un médico de cabecera, la coordinación de consultas con algunos especialistas (oftalmología, ginecología) y un seguimiento con Enfermería si procede o el paciente lo desea. Ningún hogar cuenta con atención médica, lo que hace la consulta de enfermería de vital importancia para tareas de prevención y detección de enfermedades, promoción de la salud y contención psicológica.

En tercer lugar, el Centro Médico des Charmilles (Centre Médical des Charmilles) es el centro médico de referencia del PSM. En él se desarrollan las ESI de los solicitantes cuyo alojamiento no cuenta con Enfermería, se efectúan gran parte de las consultas de medicina general, se implementa el esquema vacunal y realizan paraclínicas, administración de medicación intramuscular y endovenosa, consultas de enfermería sin número y de seguimiento.

\section{LA ENFERMERÍA TRANSCULTURAL}

El aumento y diversidad de los flujos migratorios iniciados a partir de la segunda mitad del siglo XX han transformado no sólo la composición demográfica de las sociedades, sino también sus paradigmas socioculturales. Nuevas tecnologías y enfermedades emergentes influyen desde entonces sobre la comunidad y las distintas disciplinas, tanto humanísticas como científicas. Desde de la Antropología emerge un nuevo concepto de Cultura como constructo holístico, que determina creencias, hábitos y comportamientos de quienes la comparten (11). Madeleine Leininger (1925-2012) introduce la noción de Cultura en la disciplina Enfermera al fundar, en la década de 1950, el campo de la Enfermería Transcultural (ETC). Leininger define la ETC como "un área de estudio y trabajo centrada en el cuidado y basada en la cultura, creencias, valores y prácticas de las personas en torno a su salud (...)" El unir la práctica enfermera con el conocimiento antropológico permite por ende ofrecer un mejor sistema de cuidados a usuarios culturalmente heterogéneos (12).

Aplicando sus convicciones a su propia trayectoria académica y profesional, Leininger cumuló una Maestría en Enfermería (Master of Science in Nursing) con un Doctorado en Antropología Social, desempeñó cargos docentes en las Universidades de Cincinnati y Colorado y ejerció el decanato en las de Washington y Utah. En 1970 "Enfermería y Antropología: dos mundos para unir" (Nursing and Anthropology: two worlds to blend) es su primer libro sobre Enfermería Transcultural, seguido por una intensa labor de investigación dedicada a unir la práctica sanitaria con el conocimiento antropológico. 
Para implementar un plan de cuidados adaptado a poblaciones culturalmente diversas, son fundamentales la formación teórica del profesional de la salud y la consiguiente elaboración de una consulta de Enfermería específicamente diseñada para dichas poblaciones. Por formación teórica se entiende la previa adquisición de conocimientos generales acerca de las comunidades prevalentes y sus particularidades culturales -incluyendo aspectos étnicos, religiosos y lingüísticos- que le permiten al profesional conducir la consulta en respeto de los códigos y sensibilidad del usuario. De esta manera, se realiza una recolección de datos enfocada en los factores determinantes de salud más relevantes para la atención sanitaria de poblaciones migrantes: hábitos y estilo de vida, organización socio-familiar, dimensión filosófico-religiosa, factores político-legales, económicos y educacionales (12).

EI PSM cuenta con un servicio de interpretación simultánea, en el caso de no existir un idioma de interfaz entre usuario y profesional. Es esta labor de particular importancia, ya que al acceder con mayor facilidad al lenguaje verbal y no verbal, el intérprete desempeña a menudo un rol de mediador cultural dentro del equipo multidisciplinario. Conocer las prácticas y creencias vigentes en individuos y comunidades en torno a su proceso de salud enfermedad constituye el punto de partida para diseñar objetivos e intervenciones culturalmente congruentes. Este modus operandi se basa en la convicción de que los propios usuarios pueden orientar a los profesionales respecto a los cuidados que desean o necesitan recibir y determinan las tres modalidades que guían las acciones de Enfermería al respecto: preservación, negociación y reestructuración del cuidado cultural (12). Preservar las creencias y hábitos del usuario, negociar con los medios ofrecidos por el entorno de acogida y reestructurar el plan de cuidados en función de ambas dimensiones. La calidad del diálogo y del entendimiento entre profesional y usuario son por lo tanto esenciales para que éstos definan en conjunto qué decisiones y cuidados son los más apropiados.

\section{CASO CLÍNICO}

El caso clínico presentado a continuación se basa en dos instancias de Enfermería del PSM: la consulta inicial del Accueil du Bouchet y la Evaluación de Salud Inicial (ESI) del Hogar de Saconnex (Foyer de Saconnex), respectivamente realizadas el 16 y 23 de enero de 2017. La consulta inicial se llevó a cabo sin intérprete, mientras que se dispuso para la ESI de un servicio de intérprete para el árabe.

N. es una mujer eritrea de 31 años que ingresó al territorio suizo con su hija de 6 años y embarazada de su hijo, nacido en Suiza en enero de 2017. Su idioma materno es el tigriña y domina además el árabe, pues residió en Sudán durante los últimos cuatro años. Su familia se encuentra repartida entre Eritrea y Sudán, incluido su hijo mayor de 11 años, permanecido en este último país a cargo de una amiga. Afirma su pertenencia a la religión cristiana ortodoxa, no cuenta con ningún nivel de instrucción y refiere haber desempeñado trabajo doméstico como única fuente de ingreso. Partió de Sudán en junio de 2016 para
Libia, donde relata haber sido víctima de malos tratos en repetidas ocasiones durante sus seis meses de estadía. El barco en que emprendió la travesía del Mediterráneo naufragó y tras ser auxiliada por la Marina italiana, permaneció internada tres semanas en un hospital de Milán por complicaciones relacionadas con su embarazo. Llegó finalmente al Centro de Registro suizo de Vallorbe el 23 de diciembre de 2016 para depositar su solicitud de asilo y fue asignada al cantón de Ginebra tras el nacimiento de su hijo.

N. se encuentra cursando un puerperio mediato sin complicaciones fisiológicas y no refiere antecedentes médico quirúrgicos. Relata un patrón de sueño alterado por el proceso de lactancia y se observa un buen grado de afrontamiento, a pesar de la precariedad de su situación. En efecto, su ingreso a la Comunidad europea por Italia implicará a la brevedad una sanción de No Admisión al Trámite (NEM) y la probable expulsión hacia este último país. Su desconocimiento del francés, así como su analfabetismo constituyen factores de riesgo en cuanto a sus perspectivas de integración y autonomía financiera en el país de destino. La escolarización inmediata de su hija, el buen vínculo que se observa entre ambas y su disposición para mejorar sus conocimientos actúan como factor protector en ese mismo proceso. Del cuestionario específico aplicado durante la ESI, no sobresalieron elementos suficientes para establecer un diagnóstico de síndrome postraumático vinculado con las sevicias padecidas en Libia. Tampoco se abordó el tema de la contracepción, que implica crear un vínculo terapéutico de confianza a más largo plazo.

A partir de la ESI se establecieron dos diagnósticos prioritarios en el proceso de atención de la usuaria según la taxonomía NANDA (13). En primer lugar, se identificó un Aislamiento social (00053) relacionado con diferencias culturales y desconocimiento del idioma, manifestado por ausencia de referencias y redes de apoyo. Con el objetivo de desarrollar el Soporte social (NOC 1504), se planteó como primera intervención Aumentar los sistemas de apoyo (NIC 5440), vinculando a N. con la comunidad eritrea, ya que sus representantes integrados en la sociedad ginebrina pueden actuar como interfaz cultural y a su vez ejercer un rol de contención. En segundo lugar, se apuntó a Potencializar su sociabilización (NOC 5100) y para ello incentivar su proceso de alfabetización y aprendizaje del francés, mediante los programas estatales a disposición y la red de profesores voluntarios. La próxima escolarización de su hija se considera como un factor de integración esencial y le permitirá a N. vincularse con padres suizos y extranjeros, que conforman el tejido sociodemográfico de la ciudad. El segundo diagnóstico establecido fue Riesgo de cansancio en el rol de cuidador (0062) relacionado con cuidados a hijo recién nacido e hija de seis años bajo responsabilidad exclusiva. Con el objetivo de detectar y prevenir Factores estresantes en el cuidador (NOC 2208), se orientaron las intervenciones al Apoyo en toma de decisiones (NIC 5250) y Apoyo en el rol de cuidador (NIC 7040), facilitando el acceso de N. al servicio de guardería del hogar y su enlace con el Servicio Social.

El plan de cuidados elaborado para N. apuntó principalmente a facilitar su proceso de adaptación y paulatinamente, otorgarle 
herramientas que habilitaran su integración y el de su núcleo familiar. Sin embargo, la usuaria explicitó que el cuidado de su hijo recién nacido constituía por el momento su prioridad y que no deseaba acceder inmediatamente a los programas de enseñanza de francés. El interés por preservar los hábitos y creencias de la usuaria y a su vez la voluntad de fomentar su proceso de autonomización Ilevaron al equipo de Enfermería a reestructurar el plan de cuidados. Se estableció en conjunto con $\mathrm{N}$. un nuevo cronograma para sus actividades de aprendizaje y consultas semanales de seguimiento que permitieran evaluar periódicamente el proceso de atención.

\section{REFLEXIONES FINALES}

La Cultura, en su definición holística, constituye un factor determinante en la concepción de una enfermedad, de sus causas y de su abordaje terapéutico. Diferencias ideacionales acerca del Proceso de Salud-Enfermedad pueden por lo tanto incidir notablemente en la adhesión del usuario al plan de cuidados propuesto por el profesional. Uno de los aspectos más relevantes de la atención sanitaria brindada en el PSM fue la negociación y reestructuración del cuidado observadas en la mayoría de las situaciones, incluido el caso clínico presentado. Esta dinámica se justifica por las especificidades culturales de los usuarios y hacen a menudo imprescindible la intervención de intérpretes o mediadores culturales. El resultado de este proceso conjunto entre usuario y equipo de salud puede por ende alejarse notablemente de las pautas establecidas por el paradigma sanitario suizo, él mismo producto de la cultura helvética. Dicha realidad incentiva la reflexión acerca de las pautas éticas y conceptuales que lideran la construcción de una política de salud migratoria, las herramientas teórico-prácticas necesarias para su implementación y su impacto en el PSE de la población atendida.

A través del plan de cuidados implementado en el caso clínico, se pudo comprobar la incidencia del abordaje transcultural en su elaboración y así alcanzar el objetivo propuesto para este trabajo. En efecto, el respeto por las particularidades culturales y socioeconómicas de la usuaria, así como por sus decisiones en cuanto al PSE del núcleo familiar guiaron el Proceso Enfermero y permitieron su reestructuración en base a un compromiso entre ambas partes.

Así pues, la misión del PSM se cumple mediante la decisión política de considerar la salud migratoria como una problemática pública y la consiguiente implementación de estrategias que garantizan una dotación adecuada en recursos humanos y materiales y aseguran la accesibilidad de la población diana a los servicios del Programa. El nivel de competencia de los Profesionales Médicos y de Enfermería, su capacitación en Salud Migratoria y el trabajo en red de todas las estructuras del PSM constituyen las herramientas que sostienen la continuidad y coherencia de la atención. Estas acciones conjuntas generan un impacto positivo en la calidad de la atención sanitaria de las personas migrantes y constituyen un eslabón esencial en su proceso de adaptación e integración social.
Cómo citar este artículo: Marina, K. Salud integral y migración: abordaje transcultural del Proceso Enfermero en un caso clínico del programa de salud migratoria de Ginebra, Suiza. Enfermeria (montev.). [Internet]. 2017 Dic. [citado xxxxx]; 6 (2) 45-50. Disponible en: https://doi.org/10.22235/ ech.v6i2.1512

\section{REFERENCIAS BIBLIOGRÁFICAS}

1. Parini, L. La Suisse terre d'asile: un mythe ébranlé par I'histoire. En: Revue européenne des migrations internationales, Vol. 13, n¹,1997: Págs. 51-69; DOI: 10.3406/ remi.1997. [Internet] [consultado 2017 Jun 06] Disponible en: http://www.persee.fr/doc/remi_0765-0752_1997_ num_13_1_1532

2. Häsler, AA. La barque est pleine: La Suisse, terre d'asile? La politique de la Confédération envers les réfugiés, de 1933 à 1945. Zurich: Ed. M; 1992.

3. Agencia de la ONU para los Refugiados ACNUR, La Convención de 1951: Pág. 2 [consultado 2017 Jun 06] Disponible en: http://www.acnur.org/fileadmin/scripts/doc.php?file=fileadmin/Documentos/BDL/2001/0005

4. Secrétariat d'État à la Migration (SEM), Manuel Asile et retour. Article C10 Requérants d'asile mineurs non accompagnés. Feb 2016. [Internet] [consultado 2017 Jun 06] Disponible en: https://www.sem.admin.ch/dam/data/ sem/asyl/verfahren/hb/c/hb-c10-f.pdf

5. Secrétariat d'État à la Migration (SEM), Statistique en matière d'asile 2016. Berne-Wabern: Jan 2017 [Internet] [consultado 2017 Jun 06] Disponible en: https://www. sem.admin.ch/dam/data/sem/publiservice/statistik/ asylstatistik/2016/stat-jahr-2016-kommentar-f.pdf

6. Secrétariat d'État à la Migration (SEM), Répartition des requérants d'asile selon les cantons. 2012. [consultado 2017 Jun 06] Disponible en: https://www.sem.admin.ch/sem/ $\mathrm{fr} /$ home/asyl/asylverfahren/empfang/verteilung_der_ asylsuchenden.html

7. République et Canton de Genève, Statistiques Cantonales 2016. Genève: 2017 Mar. [Internet][consultado 2017 Jun 06] Disponible en: http://www.ge.ch/statistique/domaines/apercu.asp?dom $=01 \_02_{5}$

8. International (Centre for Migration Policy Development (ICMPD). Les soins de santé pour les migrants sans papiers en Suisse. Université de Neuchâtel; 2011. [Internet] [consultado 2017 Jun 06] Disponible en: https://www.unine. ch/files/live/sites/sfm/files/nouvelles\%20publications/ factsheet_policies_fr_small.pdf

9. Bel Hammar F. Présentation du PSM. Haute École de Santé Suisse HedS-GE. Genève: 2009. [consultado 2017 Jun 06] Disponible en:https://www.ecolelasource.ch/fichiers-stages/document/Presentation_du_PSM_juin_2009.pdf

10. Hôpitaux Universitaires de Genève HUG. Réseau Santé pour Tous. Mission. Última actualización 2017 Jun 20 [Internet] [consultado 2017 Jun 06] Disponible en: https:// www.hug-ge.ch/reseau-sante-pour-tous 
11. Bonill de las Nieves C. Celdrán Mañas M. El cuidado y la cultura: Génesis, lazos y referentes teóricos en enfermería. Index Enferm [Internet]. 2012 Sep [consultado 2017 Jun 17; 21(3). Disponible en: http://scielo.isciii.es/scielo.php?script=sci_arttext\&pid=S1132-12962012000200011\&In$\mathrm{g}=\mathrm{es}$.

12. Leininger, M. Transcultural nursing: Concepts, theories, research and practices. New York: McGraw Hill, 1975 Colombus OH 1998: McGraw Hill citado en Cultura de los Cuidados, 2ㅇ Semestre, N. 6, Editorial,1999: [Internet][consultado 2017 Jun 06] Disponible en: https://rua.ua.es/ dspace/bitstream/10045/5126/1/CC_06_01.pdf

13. NANDA International. Diagnósticos enfermeros. Definiciones y clasificación 2015-2017. Barcelona: Elsevier; 2016. 